\title{
Some Potential Biochemical Markers of Leprosy
}

\author{
Ghada A. Abdel Aleem, * Hoda A. Moneib, *Sahar S. Youssef, * \\ Nahla K.Darwish; ** Mona Abdel-Azem \\ Medical Biochemistry Department, **Pathology Dep., Faculty of \\ Medicine, Tanta University; * Dermatology \& Venereology Dep; \\ *Faculty of Medicine, Ain Shams University
}

\begin{abstract}
Background: Leprosy is a chronic granulomatous infectious disease caused by the bacterium Mycobacterium leprae. Leprosy "Type 1" reactions (T1R), reversal reactions, occur in 30-40\% of borderline patients with cellular immune responses to $M$. leprae. "Type 2" reactions (T2R), also known as erythema nodosum leprosum (ENL), occur only in lepromatous (LL) and borderline lepromatous (BL) patients with a high bacterial load and little or no cellular immunity to M. leprae. Corticosteroids alleviate symptoms in $T 1 R$ and $T 2 R$, but many patients have multiple, recurrent episodes. The Objective of the present study is to verify the validity of measuring chitotriosidase activity and neopterin level, products of activated macrophages, adenosine deaminase activity and monocyte chemoattractant protein-1 (MCP-1) as markers of leprosy and to detect their values in diagnosis of different types of leprosy. Methods: This study was conducted on 15 healthy subjects and 75 leprotic patients that were classified into 5 groups [tuberculoid leprosy (TT), borderline tuberculoid $(B T)$, borderline borderline $(B B)$, borderline lepromatous $(B L)$, and lepromatous leprosy (LL)], each group formed of 15 patients, depending on clinical, bacteriological and histopathological pattern. Patients were further grouped with a $B I \geq 2$ as multibacillary $(M B, n=45)$, whereas those with $B I<2$ were grouped as paucibacillary $(P B, n=30)$. Thirty-four of the aforementioned patients were diagnosed with reactions of which 17 had type II/erythema nodosum leprosum (ENL) and 17 had type I/reversal reaction (RR). Reactions were treated using prednisolone for 12 weeks. Venous blood sample was collected from each subject and processed for estimation of the activity of chitotriosidase and adenosine deaminase, neopterin and MCP-1 levels. Results: both chitotriosidase activity and neopterin level were elevated in leprosy patients with significant elevation in $M B$ than $P B$ leprosy with significant lowering in the patients with reactional leprosy after prednisolone therapy. Adenosine deaminase activity was significantly elevated in TT, PB and reactional leprosy. MCP-1 was significantly elevated in LL, MB and ENL. Conclusion: chitotriosidase and neopterin could be considered as promising markers for differentiation of $M B$ from $P B$ patients and useful for determining the response of reactional leprosy to therapy. Adenosine deaminase could be useful in distinguishing $T T, P B$ and reactional leprosy. MCP-1 could be considered a fair marker in $L L, M B$ and ENL. In addition, these findings may provide new clues to the pathogenesis of leprosy reactions.
\end{abstract}

Key words: multibacillary (MB), paucibacillary (PB), Non-reactional leprosy (NR), erythema nodosum leprosum (ENL), reactional leprosy $(R L)$, reversal reaction $(R R)$ and healthy controls (HC). Tubercloid Leprosy (TT), Leprometous Leprosy (LL), Bordreline Lepromatous (BL), Bordreline Tubercloid (BT), Bordreline Bordreline $(B B)$. 


\section{INTRODUCTION}

Leprosy, or Hansen's disease, is a chronic infectious disease caused by Mycobacterium leprae ${ }^{(1)}$. Leprosy is primarily a granulomatous disease of the peripheral nerves and mucosa of the upper respiratory tract; skin lesions are the primary external symptom $^{(2)}$. Leprosy is still a significant public health problem. Disease prevalence has fallen due to introduction of multidrug therapy $(\mathrm{MDT}){ }^{(3)}$.

Reactions are a characteristic and clinically important aspect of Hansen's disease ${ }^{(\mathbf{1})}$. Fifty percent will experience reaction after the institution of multidrug therapy. Reaction can be severe and are an important cause of permanent nerve damage in borderline patients ${ }^{(4)}$. Reactions, a relatively common phenomenon among leprosy patients in treatment, require early detection and proper management to prevent serious sequelae. It is generally accepted that reactional states are immunologically mediated and, as such, usually improve with immunomodulatory treatments such as corticosteroids or thalidomide.

Neopterin is produced chiefly by human macrophages through their activation by T-cell-derived interferon gamma $^{(5)}$. Determination of neopterin in various body fluids provides a convenient way to monitor early events that are involved in cellmediated immune responses ${ }^{(6)}$. In malignant neoplasia, elevation of neopterin concentrations in body fluids depends on tumor type ${ }^{(7)}$.
Chitotriosidase, one of the most quantitative proteins secreted by activated macrophages, is an endoglucosaminidase belonging to family 18 glycosyl hydrolases and cleaves chitin ${ }^{(\mathbf{8}-10)}$. Its activity has been proposed as a biochemical marker of macrophage accumulation in several lysosomal diseases, especially in Gaucher's disease. ${ }^{(\mathbf{1 1}, 12)}$ Recently, Boot et al. ${ }^{(13)}$ have shown that chitotriosidase activity was elevated up to 55-fold in extracts of atherosclerotic tissue, showing a clear connection between chitotriosidase expression and lipid-laden macrophages inside human atherosclerotic vessel wall.

Adenosine deaminase (ADA), an enzyme of purine metabolism, is present in T-lymphocytes and in part regulates the lymphocytes metabolism and is also important for lymphocytic differentiation and growth ${ }^{(14)}$. Its activity appears to be necessary for an effective immune response as shown by many studies like in combined immunodeficiency disease and in typhoid fever. Besides this, increased activity of serum ADA has also been demonstrated in tubercular pleural effusion and peritoneal tuberculosis $^{(15)}$. An increased activity of serum ADA has also been demonstrated in leprosy patients. The cellular immune aberration seen in the different types of leprosy may be due to abnormal proliferation of lymphocytes in response to $\mathrm{M}$. leprae $^{(\mathbf{1 6})}$.

Monocyte chemotactic protein-1 (MCP-1), a member of the small inducible gene (SIG) family, plays a role in the recruitment of monocytes 
to sites of injury and infection. The gene for MCP1 is on chromosome 17 in region 17q11.2-q12. MPC1 has been found in the joints of people with rheumatoid arthritis where may serve to recruit macrophages and perpetuate the inflammation in the joints ${ }^{(17,18)}$.

There is no quick and easy method for identification of Mycobacterium Leprae in clinical specimens; also diagnosis of leprosy is based primarily on clinical ground. M.Leprae cannot be cultured in the laboratory $^{(\mathbf{1 9})}$. Diagnosis is often confirmed by microscopic observation of acid -fast bacilli in fresh slit skin smears. Since microscopy requires an estimated 10,000 organisms \{acidfast bacilli (AFB) $\} / \mathrm{g}$ of tissue, staining is positive for most patients with multibacillary, but is frequently negative in paucibacillary cases ${ }^{\mathbf{( 2 0 )}}$. A cutaneous nerve biopsy is frequently required to establish the diagnosis of pure neural leprosy ${ }^{(21)}$. Recently developed molecular techniques have the potential for more sensitive detection of M.Leprae but they are expensive $^{(22)}$. So, a sensitive and specific method for detection of $M$. leprae might simplify the diagnosis of leprosy.

The Objective of the present study is to verify the validity of measuring chitotriosidase activity and neopterin level, products of activated macrophages, adenosine deaminase activity and MCP-1 as markers of leprosy and to detect their values in diagnosis of different types of leprosy.

\section{SUBJECTS \& METHODS}

The present study was conducted on 15 healthy subjects as controls and
75 leprosy patients diagnosed according to World Health Organization definition of leprosy ${ }^{(3)}$. The patients came to lepra hospital in Tanta city (old leprosrium). Samples were collected during the period of 2008-2009. Patients were free of any disease except leprosy. Patients were 45 male and 30 female and their ages ranged from 22 to 70 years old. Healthy control subjects were 15 and their ages ranged from 25 to 64 years old and they included 6 males and 4 females.

Patients were clinically diagnosed and evaluated by bacteriological index in slit skin smear. Histopathological examination for skin biopsy was done to confirm the diagnosis. A standardized Case Report Form (CRF) was applied to all patients to collect data on age, sex, living in rural/urban area, family history, and history of BCG vaccination, clinical characteristics, neurological impairment, and final classification. All patients and control subjects signed an informed consent.

Patients were classified into 5 groups (TT, BT, BB, BL, and LL) depending on clinical, bacteriological and histopathological pattern according to the Ridley and Jopling's classification $^{(\mathbf{2 3})}$ as 15 lepromatous (LL), 15 borderline lepromatous (BL), 15 borderline borderline (BB), 15 borderline tuberculoid (BT) and 15 tuberculoid (TT) patients. According to WHO classification ${ }^{(3)}$, the patients were further grouped with a $\mathrm{BI} \geq 2$ as multibacillary $(\mathrm{MB}, \mathrm{n}=45)$ and included all the $\mathrm{LL}, \mathrm{BL}$ and $\mathrm{BB}$ patients, whereas those with $\mathrm{BI}<2$ were grouped as paucibacillary (PB, $\mathrm{n}=30$ ) and included the BT and TT 
patients. Thirty-four of the aforementioned patients were diagnosed with reactions of which 17 had type II/erythema nodosum leprosum ( $\mathrm{ENL} ; \mathrm{LL}=10, \mathrm{BL}=7$ ) and 17 had type $\mathrm{I} /$ reversal reaction ( $\mathrm{RR}$; $\mathrm{BB}=10, \mathrm{BL}=4, \mathrm{BT}=3)$. $\mathrm{ENL}$ was diagnosed by the acute appearance of nodular skin lesions, accompanied by fever with or without peripheral nerve pain and nerve dysfunction. RR reversal reaction typically presented as an acute inflammation of preexisting lesions and/or onset of new erythematous skin lesions.

Patients were treated with MDT according to World Health Organization guidelines ${ }^{(3)}$. Reactions were treated using prednisolone starting at $40 \mathrm{mg} /$ day and gradually tapering off over a period of 12 weeks $^{(24)}$. Clinical improvement of reactions was defined as complete subsidence of all reactional symptoms. Follow-up samples at the end of corticosteroid treatment were obtained from all reactional ENL (17) and RR (17) patients. None of the leprosy patients included in the study had neuritis.

All patients were subjected to the following:

- History taking which included personal, family history of contact with leprosy patients and the duration of the disease.

- General examination was done with special attention to the skin and peripheral nerves.

- Nerve examination and assessment of the motor function of the nerves

- Bacteriological examination by slit skin smears were done from both ear lobules and edge of active lesions. The chosen skin sites were cleaned and dried.A fold was picked up between the thumb and the finger and was squeezed tightly to render it free of blood. A small lion was made into the dermis (5mm long \& $3 \mathrm{~mm}$ deep).

- The blade should be hold at right angle to cut and used to scrap the cut surface then fixed over a flame and stained by modified ZiehlNeelsen stain and examined in 100x oil immersion field (100 GIF). The bacilli were seen as red rods against blue background.

\section{The bacteriological index (BI):}

- Zero means no bacteria seen in 100 fields, 1+ means presence 1-10 bacteria in 100 fields, 2+ means presence 1-10 bacteria in 10 fields, $3+$ means presence 1-10 bacteria in an average field, 4+ means presence 10-100 bacteria in an average field, $5+$ means presence 100-1000 bacteria in an average field, 6+ means presence many clumps of bacteria $(>1000)$ in an average field.

- Skin biopsy: Deep biopsy was done from the skin lesions in $10 \%$ formalin, and stained by Haematoxylin and Eosin to confirm the diagnosis. Diagnostic criteria for leprosy based on 1 or more of the following 3 signs:

o Hypopigmented or reddish patches with definite loss of sensation.

o Thickened peripheral nerves.

o Acid-fast bacilli on skin smears or biopsy material ${ }^{(24)}$.

Blood sample collection:

$10 \mathrm{ml}$ venous blood was collected form each subject and processed as follow; $5 \mathrm{ml}$. were added to an EDTAcontaining tube. Plasma was separated after centrifugation at $1500 \mathrm{~g}$ for 10 
min and frozen at $-70^{\circ} \mathrm{C}$ for chitotriosidase activity determination.

$5 \mathrm{ml}$ were collected in sterile test tubes and centrifuged for 10 minutes at $1500 \mathrm{~g}$, serum was separated and kept at $-70^{\circ} \mathrm{C}$ until used for estimation of neopterin, adenosine deaminase and MCP-1

1- Estimation of chitotriosidase enzyme activity according to the method described by Hollak et al. ${ }^{(11)}$

2- Estimation of serum neopterin by enzyme linked immunosorbent assay, commercial kit was obtained from IBL Immunobiological Laboratories (USA) ${ }^{(\mathbf{2 5})}$.

3- Estimation of serum MCP-1 by enzyme linked immunosorbent assay, commercial kit was obtained from RayBiotech, Inc. ${ }^{(26)}$.

4- Estimation of total ADA enzyme activity according to colorimetric method of Giusti ${ }^{(27)}$. Results were expressed as international unit (U/L) of enzyme activity of serum. One unit of ADA is defined as the amount of enzyme required to release $1 \mu \mathrm{mol}$ of ammonia/min from adenosine at standard assay conditions.

\section{Statistics:}

All the statistical analyses were processed using Statistical Program of Social Sciences (SPSS) for windows, version 10.0. Values of the measured parameters were expressed as mean value $\pm \mathrm{SD}$ and the difference between groups was determined using unpaired student's t-test for comparing patients' results with controls while paired ttest was used for comparing the results of reactional patients group before and after corticosteroids therapy, and the significance was considered at $\mathrm{p}$ values $<0.001$ up to $<0.05$.

\section{RESULTS}

Plasma chitotriosidase activity was significantly elevated in leprosy patients (132.2 \pm 15.8$)$ as compared to healthy controls(18.2 \pm 12.7$)$ from the same leprosy endemic area $(\mathrm{P}<0.001)$ (Table 1). Activity of serum chitotriosidase was significantly higher in LL, BL and BB [(209.3 \pm 135.6$), \quad(197.2 \pm 104.5)$, (191.4 \pm 112.6$)$, respectively] as compared to BT and TT $[(25.2 \pm 13.9)$, (29.3 \pm 21.3$)$, respectively] $(\mathrm{P}<0.001)$ (Table 2). Activity of plasma chitotriosidase was significantly higher in MB $(210.3 \pm 367.5)$ as compared to $\mathrm{PB}$ patients $(27.9 \pm 26.1)$ and $\mathrm{HC}(18.2 \pm 12.7)(\mathrm{P}<0.001)$, but no significant difference was found between $\mathrm{PB}(27.9 \pm 26.1)$ and $\mathrm{HC}$ $(\mathrm{P}>0.05)$ (Table 3). Reactional leprosy group showed significantly higher chitotriosidase activity $(157.9 \pm 24.7)$ as compared to non-reactional leprosy group (84.2 \pm 11.9$) \quad(\mathrm{P}<0.001)$, both were significantly higher than control group (18.2 \pm 12.7$)(\mathrm{P}<0.001)$ (table 4). Plasma chitotriosidase activity was significantly higher in ENL (274.5 \pm 484.4$)$ as compared to RR $(33.4 \pm 9.6)$ and $\mathrm{HC} \quad(18.2 \pm 12.7)$ $(\mathrm{P}<0.001)$, and significantly higher in $\mathrm{RR}$ (33.4 \pm 9.6$)$ compared to $\mathrm{HC}$ (18.2 \pm 12.7 ) (table 5). Chitotriosidase activity was observed to decline significantly following corticosteroid treatment of reactional leprosy patients $(95.3 \pm 13.5)$ compared to its level before therapy $(157.9 \pm 24.7)$ $(\mathrm{P}<0.001) \quad($ table 6$)$ and was not 
significantly different from the activity observed in non reactional leprosy patients $(84.2 \pm 11.9)(\mathrm{P}>0.05)$.

Serum neopterin showed a similar trend to chitotriosidase, with levels being significantly higher in leprosy patients $(22.8 \pm 3.9)$ as compared to healthy controls(5.9 \pm 1.9$)$ from the same leprosy endemic area $(\mathrm{P}<0.001)$ (Table 1). Neopterin level was significantly higher in LL, BL and BB $[(28.9 \pm 16.1)$, $(27.2 \pm 13.6)$, (27.8 \pm 10.9$)$, respectively] as compared to BT and TT [(15.6 \pm 5.9$)$, (11.9 \pm 6.1$), \quad$ respectively] $(\mathrm{P}<0.001)$ (Table 2). Neopterin level was significantly higher in $\mathrm{MB}$ $(27.5 \pm 18.7)$ as compared to $\mathrm{HC}$ (5.9 \pm 1.9$)$ and PB (13.6 \pm 7.2) $(\mathrm{P}<0.001)$, also significant difference was found between $\mathrm{PB}$ (13.6 \pm 7.2) and $\mathrm{HC}(5.9 \pm 1.9) \quad(\mathrm{P}<0.001)$ (Table $3)$. Reactional leprosy group showed significant higher neopterin level (24.2 \pm 3.6$)$ as compared to nonreactional leprosy group $(13.4 \pm 4.1)$ $(\mathrm{P}<0.001)$, both were significantly higher than control (table 4). Serum neopterin level was elevated in ENL (30.6 \pm 24.6$)$ as compared to RR $(22.5 \pm 3.9)$ and $\mathrm{HC} \quad(5.9 \pm 1.9)$ $(\mathrm{P}<0.001)$ (Table 5). Neopterin level was significantly lowered following corticosteroid treatment of reactional leprosy patients $(12.5 \pm 4.6)$ if compared with reactional leprosy patients before corticosteroid therapy (24.2 \pm 3.6$)(\mathrm{P}<0.001)$ (Table 6).

Adenosine deaminase activity was significantly higher in leprosy patients $(24.4 \pm 5.2)$ as compared to healthy controls $(7.8 \pm 1.2) \quad(\mathrm{P}<0.001)$ (Table 1). Adenosine deaminase activity was significantly higher in TT (25.3 \pm 5.3$)$ as compared to $\mathrm{BL}, \mathrm{BB}$,
BT and LL [(17.1 \pm 1.9$),(17.8 \pm 2.5)$, $(18.3 \pm 1.1) \quad$ and $\quad(16.9 \pm 3.6)$ respectively] $(\mathrm{P}<0.05) \quad($ Table 2$)$. Adenosine deaminase activity was significantly higher in PB $(25.4 \pm 2.4)$ as compared to $\mathrm{HC}(7.85 \pm 1.25)$ and MB $\quad(16.2 \pm 2.9) \quad(\mathrm{P}<0.05), \quad$ also significant difference was found between $\mathrm{MB}(16.2 \pm 2.9)$ and $\mathrm{HC}$ (7.85 \pm 1.25$) \quad(\mathrm{P}<0.001) \quad($ Table 3). Reactional leprosy group (29.3 \pm 3.5$)$ showed significantly higher adenosine deaminase activity as compared to non-reactional leprosy group (15.6 \pm 3.3) $(\mathrm{P}<0.05)$, both were significantly higher than control (table 4). Adenosine deaminase activity was elevated in both ENL (29.74 \pm 3.25$)$ and RR (27.36 \pm 5.36$)$ as compared to $\mathrm{HC} \quad(7.8 \pm 1.2) \quad(\mathrm{P}<0.001) \quad$ with insignificant difference between ENL and RR $\quad(\mathrm{P}>0.05) \quad($ Table 5). Adenosine deaminase activity showed insignificant difference following corticosteroid treatment of reactional leprosy patients $(24.3 \pm 3.26)$ if compared with reactional leprosy patients before corticosteroid therapy (29.3 \pm 3.56$)(\mathrm{P}>0.05)$ (table 6).

Monocyte chemoattractant protein-1 (MCP-1) was significantly high in leprosy patients $(153.4 \pm 33.2)$ as compared to healthy controls $(127.9 \pm 28.5) \quad(\mathrm{P}<0.001) \quad($ Table 1). MCP-1 was significantly higher in LL $(184.1 \pm 85.96)$ as compared to $\mathrm{BL}$, $\mathrm{BB}, \quad \mathrm{BT}$ and TT [(128.3 \pm 26.1$)$, (130.6 \pm 22.5$), \quad(132.1 \pm 16.4) \quad$ and $(129.2 \pm 20.6)$ respectively] $(\mathrm{P}<0.001)$ (Table 2). MCP-1 was significantly higher in $\mathrm{MB}(147.4 \pm 41.2)$ as compared to $\mathrm{HC}(127.9 \pm 28.5)$ and $\mathrm{PB}$ $(130.6 \pm 20.8) \quad(\mathrm{P}<0.05), \quad$ also insignificant difference was found between PB (130.6 \pm 20.8) and $\mathrm{HC}$ 
(127.9 \pm 28.5$) \quad(\mathrm{P}>0.05) \quad$ (Table 3).

Reactional leprosy group

(135.2 \pm 15.2$)$ showed insignificant difference in MCP-1 level as compared to non-reactional leprosy group (133.2 \pm 21.2$) \quad(\mathrm{P}>0.05)$, also both showed insignificant difference with control group $(\mathrm{P}>0.05)$ (table 4$)$. ENL group showed significant higher level of MCP-1 (151.3 \pm 35.1$)$ as compared to RR (131.2 \pm 25.5$)$ and $\mathrm{HC}$
$(127.9 \pm 28.5) \quad(\mathrm{P}<0.05) \quad$ with insignificant difference between RR and control group $(\mathrm{P}>0.05)$ (Table 5). MCP-1 showed insignificant difference following corticosteroid treatment of reactional leprosy patients (130.1 \pm 24.1$)$ if compared with reactional leprosy patients before corticosteroid therapy $(135.2 \pm 15.5)$ $(\mathrm{P}>0.05)$ (table 6).

Table 1: Mean values of neopterin level, chitotriosidase activity, adenosine deaminase activity and MCP-1 level across the leprosy patients group and control group

\begin{tabular}{lllll}
\hline Classification & $\begin{array}{l}\text { Neopterin } \\
\text { nmol/l }\end{array}$ & $\begin{array}{l}\text { Chitotriosidase } \\
\mathbf{n m o l} / \mathbf{m l} / \mathbf{h}\end{array}$ & $\begin{array}{l}\text { Adenosine } \\
\text { deaminase U/l }\end{array}$ & $\begin{array}{l}\text { MCP-1 } \\
\mathbf{p g} / \mathbf{m l}\end{array}$ \\
\hline Leprotic patients $(\mathrm{n}=75)$ & $22.8 \pm 3.9^{\mathbf{b}}$ & $132.2 \pm 15.8^{\mathbf{b}}$ & $24.4 \pm 5.2^{\mathbf{b}}$ & $153.4 \pm 33.2^{\mathbf{b}}$ \\
\hline Control $(\mathrm{n}=15)$ & $5.9 \pm 1.9^{\mathbf{a}}$ & $18.2 \pm 12.7^{\mathbf{a}}$ & $7.8 \pm 1.2^{\mathbf{a}}$ & $127.9 \pm 28.5^{\mathbf{a}}$ \\
\hline P-value & $\mathrm{P}<0.001$ & $\mathrm{P}<0.001$ & $\mathrm{P}<0.001$ & $\mathrm{P}<0.001$ \\
\hline
\end{tabular}

Groups bearing different initials in the same column are significantly different from each other.

Table 2: Mean values of neopterin level, chitotriosidase activity, adenosine deaminase activity and MCP-1 level across the leprosy groups and control group

\begin{tabular}{lllll}
\hline Classification & $\begin{array}{l}\text { Neopterin } \\
(\mathbf{n m o l} / \mathbf{l})\end{array}$ & $\begin{array}{l}\text { Chitotriosidase } \\
(\mathbf{n m o l} / \mathbf{m l} / \mathbf{h})\end{array}$ & $\begin{array}{l}\text { Adenosine } \\
\text { deaminase }(\mathbf{U} / \mathbf{l})\end{array}$ & $\begin{array}{l}\text { MCP-1 } \\
(\mathbf{p g} / \mathbf{m l})\end{array}$ \\
\hline $\mathrm{TT}(\mathrm{n}=15)$ & $11.9 \pm 6.1^{\mathbf{c}}$ & $29.3 \pm 21.3^{\mathbf{a}}$ & $25.3 \pm 5.3^{\mathbf{c}}$ & $129.2 \pm 20.6^{\mathbf{a}}$ \\
\hline $\mathrm{BT}(\mathrm{n}=15)$ & $15.6 \pm 5.9^{\mathbf{c}}$ & $25.2 \pm 13.9^{\mathbf{a}}$ & $18.3 \pm 1.1^{\mathbf{b}}$ & $132.1 \pm 16.4^{\mathbf{a}}$ \\
\hline $\mathrm{BB}(\mathrm{n}=15)$ & $27.8 \pm 10.9^{\mathbf{b}}$ & $191.4 \pm 112.6^{\mathbf{b}}$ & $17.8 \pm 2.5^{\mathbf{b}}$ & $130.6 \pm 22.5^{\mathbf{a}}$ \\
\hline $\mathrm{BL}(\mathrm{n}=15)$ & $27.2 \pm 13.6^{\mathbf{b}}$ & $197.2 \pm 104.5^{\mathbf{b}}$ & $17.1 \pm 1.9^{\mathbf{b}}$ & $128.3 \pm 26.1^{\mathbf{a}}$ \\
\hline $\mathrm{LL}(\mathrm{n}=15)$ & $28.9 \pm 16.1^{\mathbf{b}}$ & $209.3 \pm 135.6^{\mathbf{b}}$ & $16.9 \pm 3.6^{\mathbf{b}}$ & $184.1 \pm 85.9^{\mathbf{b}}$ \\
\hline $\mathrm{HC}(\mathrm{n}=15)$ & $5.9 \pm 1.9^{\mathbf{a}}$ & $18.2 \pm 12.7^{\mathbf{a}}$ & $7.8 \pm 1.2^{\mathbf{a}}$ & $127.9 \pm 28.5^{\mathbf{a}}$ \\
\hline $\mathrm{P}-\mathrm{value}$ & $\mathrm{P}<0.001$ & $\mathrm{P}<0.001$ & $\mathrm{P}<0.05$ & $\mathrm{P}<0.001$ \\
\hline
\end{tabular}

Groups bearing different initials in the same column are significantly different from each other. 
Table 3: Mean values of neopterin level, chitotriosidase activity, adenosine deaminase activity and MCP-1 level across the multibacillary and paucibacillary leprosy patients and healthy control.

\begin{tabular}{lllll}
\hline Classification & $\begin{array}{l}\text { Neopterin } \\
\mathbf{n m o l} / \mathbf{l}\end{array}$ & $\begin{array}{l}\text { Chitotriosidase } \\
\mathbf{n m o l} / \mathbf{m l} / \mathbf{h}\end{array}$ & $\begin{array}{l}\text { Adenosine } \\
\text { deaminase } \mathbf{~} / \mathbf{l}\end{array}$ & $\begin{array}{l}\text { MCP-1 } \\
\mathbf{p g} / \mathbf{m l}\end{array}$ \\
\hline $\mathrm{MB}(\mathrm{n}=45)(\mathrm{BB}+\mathrm{BL}+\mathrm{LL})$ & $27.5 \pm 18.7^{\mathbf{c}}$ & $210.3 \pm 367.5^{\mathbf{b}}$ & $16.2 \pm 2.9^{\mathbf{c}}$ & $147.4 \pm 41.2^{\mathbf{b}}$ \\
\hline $\mathrm{PB}(\mathrm{n}=30)(\mathrm{TT}+\mathrm{BT})$ & $13.6 \pm 7.2^{\mathbf{b}}$ & $27.9 \pm 26.1^{\mathbf{a}}$ & $25.4 \pm 2.4^{\mathbf{b}}$ & $130.6 \pm 20.8^{\mathbf{a}}$ \\
\hline $\mathrm{HC}(\mathrm{n}=15)$ & $5.9 \pm 1.9^{\mathbf{a}}$ & $18.2 \pm 12.7^{\mathbf{a}}$ & $7.85 \pm 1.25^{\mathbf{a}}$ & $127.9 \pm 28.5^{\mathbf{a}}$ \\
\hline $\mathrm{P}$-value & $\mathrm{P}<0.001$ & $\mathrm{P}<0.001$ & $\mathrm{P}<0.05$ & $\mathrm{P}<0.05$ \\
\hline
\end{tabular}

Groups bearing different initials in the same column are significantly different from each other.

Table 4: Mean values of neopterin level, chitotriosidase activity, adenosine deaminase activity and MCP-1 level across the reactional, non-reactional leprosy patients groups and control group

\begin{tabular}{lllll}
\hline Classification & $\begin{array}{l}\text { Neopterin } \\
\mathbf{n m o l} / \mathbf{l}\end{array}$ & $\begin{array}{l}\text { Chitotriosidase } \\
\mathbf{n m o l} / \mathbf{m l} / \mathbf{h}\end{array}$ & $\begin{array}{l}\text { Adenosine } \\
\text { deaminase U/l }\end{array}$ & $\begin{array}{l}\text { MCP-1 } \\
\mathbf{p g} / \mathbf{m l}\end{array}$ \\
\hline Reactional leprosy $(\mathrm{n}=34)$ & $24.2 \pm 3.6^{\mathbf{c}}$ & $157.9 \pm 24.7^{\mathbf{c}}$ & $29.3 \pm 3.5^{\mathbf{c}}$ & $135.2 \pm 15.2^{\mathbf{a}}$ \\
\hline Non-reactional leprosy $(\mathrm{n}=41)$ & $13.4 \pm 4.1^{\mathbf{b}}$ & $84.2 \pm 11.9^{\mathbf{b}}$ & $15.6 \pm 3.3^{\mathbf{b}}$ & $133.2 \pm 21.2^{\mathbf{a}}$ \\
\hline $\mathrm{HC}(\mathrm{n}=15)$ & $5.9 \pm 1.9^{\mathbf{a}}$ & $18.2 \pm 12.7^{\mathbf{a}}$ & $7.85 \pm 1.25^{\mathbf{a}}$ & $127.9 \pm 28.5^{\mathbf{a}}$ \\
\hline $\mathrm{P}$-value & $\mathrm{P}<0.001$ & $\mathrm{P}<0.001$ & $\mathrm{P}<0.05$ & $\mathrm{P}>0.05$ \\
\hline
\end{tabular}

Groups bearing different initials in the same column are significantly different from each other.

Table 5: Mean values of neopterin level, chitotriosidase activity, adenosine deaminase activity and MCP-1 level across the RR, ENL and control groups

\begin{tabular}{|c|c|c|c|c|}
\hline Classification & $\begin{array}{l}\text { Neopterin } \\
\text { nmol/l }\end{array}$ & $\begin{array}{l}\text { Chitotriosidase } \\
\mathrm{nmol} / \mathrm{ml} / \mathrm{h}\end{array}$ & $\begin{array}{l}\text { Adenosine } \\
\text { deaminase U/I }\end{array}$ & $\begin{array}{l}\text { MCP-1 } \\
\text { pg/ml }\end{array}$ \\
\hline $\mathrm{RR}(\mathrm{n}=17)(10 \mathrm{BB}+4 \mathrm{BL}+3 \mathrm{BT})$ & $22.5 \pm 3.9^{\mathbf{c}}$ & $33.4 \pm 9.6^{\mathbf{c}}$ & $27.36 \pm 5.36^{\mathrm{b}}$ & $131.2 \pm 25.5^{\mathrm{a}}$ \\
\hline $\mathrm{ENL}(\mathrm{n}=17)(10 \mathrm{LL}+7 \mathrm{BL})$ & $30.6 \pm 24.6^{6}$ & $274.5 \pm 484.4^{b}$ & $29.74 \pm 3.25^{b}$ & $151.3 \pm 35.1^{b}$ \\
\hline $\mathrm{HC}(\mathrm{n}=15)$ & $5.9 \pm 1.9^{\mathrm{a}}$ & $18.2 \pm 12.7^{\mathrm{a}}$ & $7.85 \pm 1.25^{\mathrm{a}}$ & $127.9 \pm 28.5^{\mathrm{a}}$ \\
\hline P-value & $\mathrm{P}<0.001$ & $\mathrm{P}<0.001$ & $\mathrm{P}<0.001$ & $\mathrm{P}<0.05$ \\
\hline
\end{tabular}

Table 6: Mean values of neopterin level, chitotriosidase activity, adenosine deaminase activity and MCP-1 level across the reactional, reactional group after therapy and control group

\begin{tabular}{lllll}
\hline Classification & $\begin{array}{l}\text { Neopterin } \\
\mathbf{n m o l} / \mathbf{l}\end{array}$ & $\begin{array}{l}\text { Chitotriosidase } \\
\mathbf{n m o l} / \mathbf{m l} / \mathbf{h}\end{array}$ & $\begin{array}{l}\text { Adenosine } \\
\text { deaminase U/l }\end{array}$ & $\begin{array}{l}\mathbf{M C P - 1} \\
\mathbf{p g} / \mathbf{m l}\end{array}$ \\
\hline Reactional leprosy $(\mathrm{n}=34)$ & $24.2 \pm 3.6^{\mathbf{c}}$ & $157.9 \pm 24.7^{\mathbf{c}}$ & $29.3 \pm 3.5^{\mathbf{b}}$ & $135.2 \pm 15.2^{\mathbf{a}}$ \\
\hline $\begin{array}{l}\text { Reactional leprosy }(\mathrm{n}=34) \\
12 \text { weeks after therapy }\end{array}$ & $12.5 \pm 4.6^{\mathbf{b}}$ & $95.3 \pm 13.5^{\mathbf{b}}$ & $24.3 \pm 3.2^{\mathbf{b}}$ & $130.1 \pm 24.1^{\mathbf{a}}$ \\
\hline $\mathrm{HC}(\mathrm{n}=15)$ & $5.9 \pm 1.9^{\mathbf{a}}$ & $18.2 \pm 12.7^{\mathbf{a}}$ & $7.85 \pm 1.25^{\mathbf{a}}$ & $127.9 \pm 28.5^{\mathbf{a}}$ \\
\hline $\mathrm{P}$-value & $\mathrm{P}<0.001$ & $\mathrm{P}<0.001$ & $\mathrm{P}<0.001$ & $\mathrm{P}>0.05$ \\
\hline
\end{tabular}

Groups bearing different initials in the same column are significantly different from each other. 


\section{DISCUSSION}

Leprosy is a chronic granulomatous disease of the skin and peripheral nerves caused by Mycobacterium leprae $^{(\mathbf{1})}$. The pathogenesis and thus the clinical features reflect variable degree to which cell-mediated immunity (CMI) is expressed ${ }^{(28)}$. Lepromatous leprosy (LL) represents a failure of CMI specifically towards M. leprae, with absence of activated lymphocytes and active macrophages, meaning that nerve damage is slow and gradual. In tuberculoid leprosy (TT), CMI is strongly expressed so that the infection is restricted to one or a few skin sites and peripheral nerves. Between those two polar forms lie the borderline forms of the disease, with the extent of the disease reflecting the balance between CMI and the bacillary load ${ }^{(29)}$. Borderline patients; borderline tuberculoid (BT), borderline borderline (BB), and borderline lepromatous (BL), are immunologically unstable and at risk of developing type 1 reversal reaction which is a delayed hypersensitivity reaction caused by increased recognition of $M$. leprae antigens in skin and nerves ${ }^{(30)}$. Type 2 reaction; erythema nodosum leprosum (ENL), is due to immune complex deposition and occurs in BL and LL patients ${ }^{(29)}$.

The tissue damage occurring in leprosy is exacerbated during episodes of reactions ${ }^{(31)}$. The acute inflammation associated with reactions causes irreversible tissue damage and nerve destruction; thus, early detection of leprosy reactions is a key priority ${ }^{(\mathbf{2 9})}$. If reactions are detected early and adequately treated, permanent nerve damage might be prevented $^{(31)}$. With the current emphasis on the integration of leprosy control activities into the general health-care services ${ }^{(3)}$, there is a need to laboratory markers to detect leprosy patients at the early stages, to aid clinical diagnosis, to detect reaction early and to monitor treatment efficacy. Several approaches have been attempted, with mixed results.

Chitotriosidase, one of the most quantitative proteins secreted by activated macrophages, is a human chitinase member of family 18 glycosyl hydrolases ${ }^{(8-10)}$. It is synthesized as a $50-\mathrm{kDa}$ protein containing a $39-\mathrm{kDa}$ N-terminal catalytic domain, a hinge region, and a C-terminal chitin-binding domain. It is predominantly secreted but in part processed into a $39-\mathrm{kDa}$ form that accumulates in lysosomes. In the blood stream, the secretory $50-\mathrm{kDa}$ chitotriosidase occurs predominantly, whereas in tissues, the $39-\mathrm{kDa}$ form is also abundant ${ }^{\mathbf{1 0})}$. Chitotriosidase is synthesized exclusively by activated macrophages, and its activity has been proposed as a biochemical marker of macrophage accumulation in several lysosomal diseases and is a valuable tool for monitoring the efficacy of therapy especially in Gaucher's disease ${ }^{(11)}$. Increased chitotriosidase activity has been found within atherosclerotic lesions, in which cholesterol-laden foam cells reside ${ }^{(32)}$. Elevated serum chitotriosidase activity has been reported in sarcoidosis and tuberculous pleural effusions ${ }^{(33-34)}$. 
The crucial role of the macrophage in leprosy prompted us to look at chitotriosidase activity in the plasma of leprosy patients and healthy controls mainly from leprosy endemic areas. In the present study, plasma chitotriosidase activity was elevated in leprosy patients as compared to healthy controls; also, it was elevated in $\mathrm{MB}$ patients as compared to $\mathrm{PB}$ patients or healthy controls. $\mathrm{MB}$ leprosy is characterized by an abundant macrophage infiltrate with many macrophages showing foamy morphology ${ }^{(23)}$, also, that result was evidenced by Iyer et al. ${ }^{(35)}$ who found positivity for chitotriosidase, which was localized within the macrophages, by immunohistochemical staining of skin biopsies from $6 \mathrm{MB}$ patients (LL/BL) with high plasma chitotriosidase activity. This suggested that these macrophages are the active producers of chitotriosidase activity detected in MB serum. A subset of CD68+ macrophages was positive for chitotriosidase. ${ }^{(35)} \quad$ Similar observations have also been reported for foamy macrophages in atherosclerotic plaques, where only a sub-population of the cells was positive for chitotriosidase ${ }^{(\mathbf{1 3})}$.

In the present work, chitotriosidase activity was higher in reactional leprosy than non-reactional group and that result was in disagreement with the results of Iyer et al. ${ }^{(35)}$ who reported that chitotriosidase activity is independent of the reaction state in the leprosy patients. This controversy might be due to the difference in the number of the cases examined by both studies, the stage of reaction at which the samples were taken or the different duration of illness. Also, chitotriosidase activity was higher in ENL as compared to patients with reversal reaction and healthy control. RR patients showed manifest lowering of chitotriosidase activity as compared to ENL patients but it was significantly higher than healthy control group. These results were in disagreement with the results of Iyer et $\boldsymbol{a l} .{ }^{(35)}$ as they reported lowering of chitotriosidase activity of RR group but with insignificant difference compared to their control group, that difference might be due to the difference in the number of RR patients as Iyer et al. ${ }^{(35)}$ examined three RR patients only. The results of the current study may reflect the inherently different nature of the two reactions. $\mathrm{RR}$ is associated with an increased CMI whereas; ENL is thought to be an immune complex disease with some involvement of the CMI. Chitotriosidase activity declined in reactional leprosy patients on treatment with prednisolone. This was supported by in vitro data showing lack of induction of chitotriosidase during dexamethasone-induced polarization of monocytes to macrophages. The dexamethasonedriven polarization of the macrophages was confirmed, for instance, by analysis of the induction of CD163 at the cell surface ${ }^{(36)}$.

Human chitotriosidase has many pleiotropic effects as it is a component of the innate immunity involved in protection against chitin containing pathogens. Also, variants of chitotriosidase affecting its activity are associated with Gram-negative bacteremia in children undergoing 
therapy for acute myeloid leukemia. However, M. leprae is not known to contain chitin in its cell wall/membrane fraction $^{(\mathbf{1 0 , 1 1})}$. Alternatively, increased chitotriosidase activity in leprosy may be an indirect phenomenon related to lipid overloading of lysosomes in macrophages ${ }^{(32)}$.

Neopterin is a pteridine compound synthesized from guanosine triphosphate (GTP) via GTP cyclohydrolase I in activated macrophages. It is synthesized by macrophages upon stimulation with the T-cell-derived cytokine interferongamma and is indicative of a proinflammatory immune status. Neopterin is considered as an early, specific and sensitive marker of cellmediated immune (CMI) activation ${ }^{(5)}$. In vivo, determination of neopterin in various body fluids provides a convenient way to monitor early events that are involved in cellmediated immune responses in humans under the control of $\mathrm{T}$ helper cells type $1^{(6)}$.

In the current study, serum neopterin showed significantly higher level in leprosy patients as compared to healthy controls, also, it was significantly higher in LL, BL and BB as compared to BT and TT. The increased neopterin level in the present study is consistent with increased macrophages activity in leprosy patients as neopterin is a monocyte-macrophage activation product. Also, neopterin has been previously recorded to be elevated in leprosy in general and lepra reaction in particular ${ }^{(6,7)}$ and also in other diseases associated with macrophage activation like tuberculosis ${ }^{(37)}$.
Neopterin level was significantly higher in $\mathrm{MB}$ as compared to $\mathrm{HC}$ and $\mathrm{PB}$, also significant difference was found between $\mathrm{PB}$ and $\mathrm{HC}$. As CMI plays an important role in determining the leprosy spectrum and PB leprosy is associated with strong CMI, which declines progressively towards the lepromatous end of the spectrum ${ }^{(23}$, 29), so, it seems paradoxical that the present study showed higher levels of neopterin in MB patients. These higher neopterin levels could be a result of the sheer large numbers of macrophages recruited in MB leprosy. On the other hand, PB leprosy has a more limited tissue distribution of macrophages resulting in lower neopterin levels in circulation in PB if compared with $\mathrm{MB}$ despite a strong activation of the $\mathrm{CMI}^{(38)}$.

Serum neopterin level was significantly elevated in ENL and RR as compared to HC. Reactional leprosy group showed significantly higher neopterin level as compared to non-reactional leprosy group, both were significantly higher than control. The result of the present study was in agreement with those of Hamerlinck et al. $^{(7)}$ and Faber et al. ${ }^{(6)}$ who suggested that CMI activation plays a large role in reactional states ${ }^{(\mathbf{3 9})}$. Other studies looked at the profiles of serum neopterin associated with the leprosy spectrum and reactions with often contradictory results which may be due to the different patients populations involved in the study, low number of studied reactive group, duration of illness or the use of different method for analysis ${ }^{(35,36,38)}$.

In the present study, neopterin level showed significant lowering following corticosteroid treatment of 
reactional leprosy patients if compared with reactional leprosy patients before corticosteroid therapy. Corticosteroids, the primary treatment modality for reactions ${ }^{(40)}$, cause a decrease in the number of circulating lymphocytes and monocytes and decreased production of cytokines such as IFN- $\gamma$, IL- 1 , TNF- $\alpha$ and IL$2 \mathrm{R}^{(41)}$ and neopterin expression ${ }^{(6,7)}$. The result of the present study was in agreement with that of Hamerlinck et $\boldsymbol{a l} .^{(7)}$ but it is in disagreement with those of Iyer et al. ${ }^{(35,36)}$, such contradictory results may be due to the difference in the timing of taking the blood samples during the course of reaction, the presence of other associated factors affecting the neopterin level, the difference in the number of the patients who was taken in the other study as they examined a smaller number of patients or due to the probable risk for development of subsequent episodes of reaction during the treatment course.

Adenosine deaminase (ADA) (EC 3.5.4.4), an enzyme of purine metabolism, in part regulates the lymphocytes metabolism and is also important for lymphocytic differentiation and growth $^{(\mathbf{1 4})}$. It is present in lymphocytes in high concentration. The level of enzyme in T-lymphocytes varies according to cellular differentiation ${ }^{(\mathbf{1 5}, \mathbf{1 6})}$. Increased activity of serum ADA has been demonstrated in lymphocytic proliferative diseases as tubercular pleural effusion ${ }^{(\mathbf{4 2})}$ and peritoneal tuberculosis ${ }^{(15)}$.

The present work showed that serum ADA activity is significantly higher in leprosy patients in comparison with control group with over predominance in tubercloid leprosy. These results are concomitant with lymphocytic overactivity in tubercloid leprosy. Adenosine deaminase activity was significantly higher in both $\mathrm{MB}$ and $\mathrm{PB}$ as compared to $\mathrm{HC}$, also, it was significantly higher in $\mathrm{PB}$ than in $\mathrm{MB}$, this indicates that ADA level could be used for diagnosis of $\mathrm{MB}$ as well as PB because slit skin smear (SSS) is frequently negative in paucibacillary cases $^{(\mathbf{4 3})}$. Reactional leprosy group showed significantly higher adenosine deaminase activity as compared to non-reactional leprosy group, both were significantly higher than control. Adenosine deaminase activity was elevated in both ENL and RR as compared to $\mathrm{HC}$, with insignificant difference between both ENL and RR as regard adenosine deaminase activity. Adenosine deaminase activity showed insignificant difference following corticosteroid treatment of reactional leprosy patients when compared with reactional leprosy patients before corticosteroid therapy.

Altered serum adenosine deaminase (ADA) levels have been recorded in various diseases involving lymphocytes and/or lymphoreticular system including leprosy ${ }^{(\mathbf{1 6}, 44)}$. Nigam et al., ${ }^{(45)}$ reported high significant activity of adenosine deaminase in leprosy patient in comparison with control group but with lepromatous leprosy predominance which is in disagreement with the present study results. Also, Nigam et al. $^{(45)}$ reported higher activity of adenosine deaminase in $\mathrm{MB}$ and $\mathrm{PB}$ which is in agreement with the present study results. Suri Babu et al. ${ }^{(16)}$ observed that serum ADA levels were elevated 
in tuberculoid as well as lepromatous cases as compared to control subjects. On the other hand, Dayal et al., (44) reported that ADA levels gradually increases from LL to TT spectrum. Chaudhary et al. ${ }^{(46)}$ have also shown that serum ADA levels may not run exactly parallel with the conventional parameters of cell mediated immunity in leprosy patients. Adenosine deaminase level was concerned with the lymphocyte activities which are more predominant in tubercloid leprosy and so, ADA activity might significantly increase in tubercloid leprosy as what occurred in the present study. However, the controversy between the present study results and the other studies may be due to firstly; ADA is also present in monocytes and increases tremendously during their maturation into macrophages ${ }^{(14)}$. Secondly; Lymphocyte ADA level estimation also incorporates B-lymphocyte ADA which is not at all involved in cell mediated immune response ${ }^{(45)}$. Thirdly; macrophages activities are more predominant in lepromatous leprosy but not lymphocytes ${ }^{(2,4)}$. The difference between the results of the present study and other studies ${ }^{(45)}$ might be due to the difference of the duration of illness between patients in those studies also, as the overall activity of the enzyme is elevated in leprosy; the cellular immune aberration seen in the different types of leprosy may be due to abnormal proliferation of different subsets of lymphocytes in response to M. leprae. Increase in ADA activity particularly in lymphocytes has been attributed by various workers to increased lymphocyte proliferation as a result of antigenic stimulation ${ }^{(23)}$.

The present study showed that serum ADA activity increased in leprosy patients particularly more in lepra reactions. This indicates its potential for being used as a marker of leprosy in general and lepra reactions in particular. These results agree with the results of Nigam et $\boldsymbol{a l l}^{(45)}$ who found high serum ADA levels in patients of leprosy with reaction. This may be due to increased lymphoreticular activity during the reactional phases and reactional leprosy in comparison with other groups included in the study.

Chemokines are a family of small (8-10 $\mathrm{kDa})$, inducible, secreted cytokines with chemotactic and activating effects on different leucocyte subsets and are divided into $\mathrm{C}-\mathrm{X}-\mathrm{C}$ and $\mathrm{C}-\mathrm{C}$ subfamilies. Chemokines provide key stimuli for directing leucocytes to areas of injury $^{(47)}$. MCP-1 is a basic protein consisting of 76 amino acids and is classified as a part of the C-C subfamily of chemokines (CCL2). MCP-1, pro-inflammatory cytokine, is constitutively produced by a variety of cell types, including monocytes, smooth muscle cells and endothelial cells, and its expression can be enhanced following induction by oxidative stress, cytokines or growth factor. MCP1 has been called small inducible cytokine A2 (SCYA2) or monocyte chemotactic and activating factor (MCAF). It exerts strong chemoattractant effects on monocytes, macrophages and lymphocytes ${ }^{(26)}$. Indeed, MCP-1 shows chemotaxis specific to monocytes and is related to the manifestation of surface 
desmosomal molecules on monocytes at inflammation sites, association with endothelial cells and exudation into the subendothelium ${ }^{(17,18)}$.

In the present study, MCP-1 was significantly higher in leprosy patients as compared to healthy controls. It was significantly higher in $\mathrm{LL}$ as compared to $\mathrm{BL}, \mathrm{BB}, \mathrm{BT}$ and TT. MCP-1 was significantly higher in $\mathrm{MB}$ as compared to $\mathrm{HC}$ and $\mathrm{PB}$, also insignificant difference was found between PB and HC. Reactional leprosy group showed insignificant difference in MCP-1 level as compared to non-reactional leprosy and control groups. ENL group showed significant higher level of MCP-1 as compared to RR and $\mathrm{HC}$, also, insignificant difference between $\mathrm{RR}$ and control group was shown in the present study. MCP-1 showed insignificant difference following corticosteroid treatment of reactional leprosy patients compared with reactional leprosy patients before corticosteroid therapy.

The high level of MCP-1 in LL in the present study was in agreement with the results of Mendonça et al. ${ }^{(48)}$ who reported that, the immunologic basis of the polar types of leprosy is explained by the differences of cytokine expressions in the lesions and as the skin infiltrating cells of lepromatous leprosy are mainly composed of macrophages, chemokines including MCP-1 seem to be responsible for the recruitment of these cells. Also, the present study results supported by the finding of Kirkaldy et al. ${ }^{(49)}$ who suggested that, the chemokines and their receptors, which are known to chemoattract $\mathrm{T}$ lymphocytes and macrophages, are involved in assembling the cellular infiltrate found in lesions across the leprosy spectrum. In the present study, MCP-1 was shown to be raised in type 2 reactions (ENL). That results were expected as ENL is a reaction occurs mostly on top of lepromatous leprosy patients whom MCP-1 was significantly raised and in the present study ENL occurred in 10 patients with lepromatous leprosy. However, the result of the present study is in disagreement with that of Stefani et al. $^{(\mathbf{5 0})}$ who reported insignificant difference in MCP-1 level between ENL and RR leprosy patients

Serum MCP- 1 levels are known to be significantly correlated with the serum angiotensin converting enzyme (ACE) levels in sarcoidosis ${ }^{(\mathbf{1 8})}$. Serum ACE is known to be elevated in leprosy, and that is roughly proportional to the extent of infection $^{(51)}$. Therefore, it is conceivable that the elevation of serum MCP- 1 in leprosy correlates with the severity of the disease. Although the significance of increased serum MCP-1 in leprosy patients is unknown, the reduction of experimental granuloma by antiMCP-1 antiserum in vivo suggests that increased serum MCP-1 levels in leprosy are due to granuloma formation $^{(17)}$.

\section{CONCLUSION}

Leprosy is still a significant public health problem. Gharbia is an Egyptian Governorate in the center of Delta which is known to harbor many leprosy patients ${ }^{(\mathbf{5 2})}$. Reactional state is a common reason for patients to seek consultation $^{(4)}$. The goal of this study 
was to screen some potential blood markers in leprosy in general and in lepra reactions in particular. Plasma chitotriosidase activity and serum neopterin level are potentially useful markers in distinguishing $\mathrm{MB}$ from PB leprosy and in monitoring response to therapy in reactional leprosy. Neopterin showed high statistically significant increased levels in patients with paucibacillary leprosy compared to control group. So, neopterin can be used to diagnosis paucibacillary leprosy as slit skin smear (SSS) is frequently negative in paucibacillary cases ${ }^{(43)}$. Adenosine deaminase is considered as a potentially useful marker in distinguishing TT from other types of leprosy due to lymphocytic over activity in TT and it is useful in differentiation reactional from non reactional leprosy but is not useful in monitoring response to therapy in reactional leprosy. MCP-1 is useful in distinguishing $\mathrm{LL}$ and in differentiating $\mathrm{MB}$ from $\mathrm{PB}$ leprosy and it is considered as a promising marker for detection of ENL. The identification of $\mathrm{T} 1 \mathrm{R}$ and $\mathrm{T} 2 \mathrm{R}$ markers can contribute to their early diagnosis and monitoring of treatment efficacy. Moreover, in view of the difficulty in obtaining lesional biopsies and peripheral blood mononuclear cells (PBMC) under field conditions and the relative ease of blood assays, measurement of cytokines and other soluble cellular products in circulation was better to be used as an alternative diagnostic and predictive marker. Nevertheless, the association of these markers with disease should be interpreted with caution.

\section{REFERENCES}

1. Sasaki S., Takeshita F., Okuda K. and Ishii N. (2001): Mycobacterium leprae and leprosy: a compendium. Microbiol. Immunol., 45 (11): 729-36.

2. Ryan K.J., Ray C.G. and Sherris J.C. (2004): Sherris Medical Microbiology, $4^{\text {th }}$ ed., McGraw Hill, 451.

3. World Health Organization (WHO) (2010): Leprosy Available at www.who.org. Retrieved 2010-3-2.

4. James W.D., Berger T.G. and Elston D.M. (2006): Clinical Dermatology, $10^{\text {th }}$ ed., 342-352.

5. Woloszczuk W., Troppmair J., Leiter E., Flener R., Schwarz M., Kovarik J., Pohanka E., Margreiter R.R. and Huber C. (1986): Relationship of interferon-gamma and neopterin levels during stimulation with alloantigens in vivo and in vitro. Transplantation 41:716-719.

6. Faber W.R., Iyer A.M., Fajardo T.T., Dekker T., Villahermosa L.G., Abalos R.M. and Das P.K. (2004): Serial measurement of serum cytokines, cytokine receptors and neopterin in leprosy patients with reversal reactions. Lepr. Rev., 75:274-281.

7. Hamerlinck F.F., Klatser P.R., Walsh D.S., Bos J.D., Walsh G.P. and Faber W.R. (1999): Serum neopterin as a marker for reactional states in leprosy. FEMS Immunol. Med. Microbiol., 24:405-409.

8. Boot R.G., Renkema G.H., Strijland A., van Zonneveld A.J. and Aerts J.M. (1995): Cloning of a cDNA encoding 
chitotriosidase, a human chitinase produced by macrophages. J. Biol. Chem., 270:26252-26256.

9. Hakala B.E., White C. and Recklies A.D. (1993): Human cartilage gp-39, a major secretory product of articular chondrocytes and synovial cells, is a mammalian member of chitinase protein family. J. Biol. Chem., 268: 25803-25810.

10. Renkema G.H., Boot R.G., Au F.L., Donker-Koopman W.E., Strijland A., Muijsers A.O., Hrebicek M. and Aerts J.M. (1998): Chitotriosidase, a chitinase, and the 39-kDa human cartilage glycoprotein, a chitinbinding lectin, are homologues of family 18 glycosyl hydrolases secreted by human macrophages. Eur. J. Biochem., 15;251 (12):504-509.

11. Hollak C.E., van Weely S., van Oers M.H. and Aerts J.M. (1994): Marked elevation of plasma chitotriosidase activity: a novel hallmark of Gaucher disease. J. Clin. Invest., 93:12881292.

12. Guo Y., He W., Boer A.M., Wevers R.A., de Bruijn A.M., Groener J.E., Hollak C.E., Aerts J.M., Galjaard H. and van Diggelen O.P. (1995): Elevated plasma chitotriosidase activity in various lysosomal storage disorders. J. Inher. Metab. Dis., 18:717-722.

13. Boot R.G., van Achterberg T.A., van Aken B.E., Renkema G.H., Jacobs M.J., Aerts J.M. and de Vries C.J. (1999): Strong induction of members of the chitinase family of proteins in atherosclerosis: chitotriosidase and human cartilage gp-39 expressed in lesion macrophages. Arterioscler. Thromb. Vasc. Biol., 19: 687-694.

14. Fischer D., Martin B. and Wayden V. (1976): A role of adenosine deaminase in human monocyte maturation. J. Clin. Invest., 58:399-407.

15. Bhargava D.K., Gupta M., Nijhawan S., Dasarathy S. and Kushwaha A.K. (1990): ADA in peritoneal tuberculosis: Diagnostic value in ascitic fluid and serum. Tubercle 71:121-6.

16. Suri Babu S.S., Kannan K.B., Katoch V.M. and Bharadwaj V.P. (1990): Adenosine deaminase activity in leprosy. Indian J. Lepr., 62:473-7.

17. Ichiyasu H., Suga M., Iyonaga K. and Ando M. (2001): Role of monocyte chemoattractant protein-1 in Propionibacterium acnes-induced pulmonary granulomatosis. Microsc. Res. Tech., 53:288-297.

18. Iyonaga K., Suga M., Ichiyas H., Yamamoto T., Hiraga Y. and Ando M. (1998): Measurement of serum monocyte chemoattractant protein-1 and its clinical application for estimating the activity of granuloma formation in sarcoidosis. Sarcoidosis Vasc. Diffuse Lung Dis., 15(2):165-172.

19. Clark-Curtiss J.F., Jacobs W.R. and Docherty M.A. (1985): Molecular analysis of DNA and construction of cosmid libraries of M. leprae. J. Bacteriol., 161:1093-1102.

20. Revankar C.R., Karjivkar V.G., Gurav V.J. and Ganapati R. (1989): Clinical assessment of paucibacillary leprosy under multidrug therapy -Three years 
follow-up study. Ind. J. of Lepr., 61:355- 359.

21. Jacob M. and Mathai R. (1988): Diagnosis effiacacy of cutaneous nerve biopsy in primary neuritic leprosy .Int. J. Lep., 56:56-60.

22. Pham Dang B., Koichi S., Le Thi P., Tran Man C., Norihisa I. and Tran Hau K. (2009): Evaluation of polymerase chain reaction-based detection of Mycobacterium leprae for the diagnosis of leprosy. Japanese Dermatological Association 36(5): $269-276$.

23. Ridley D.S. and Jopling W.H. (1966): Classification of leprosy according to immunity. A fivegroup system. International Journal of Leprosy and Other Mycobacterial Diseases 34: 255273.

24. World Health Organization (WHO) (1997): A guide to eliminating leprosy as a public health problem. WHO/LEP/97.7.

25. Westermann J., Thiemann F., Gerstner L., Kozak I., Bertsch T. and Krüger C. (2000): Evaluation of a new simple and rapid Enzyme Linked Immunosorbent Assay kit for neopterin determination. Clin. Chem. Lab. Med., 38(4): 345353.

26. Leonard E.J. and Yoshimura T. (1990): Human monocyte chemoattractant protein-1 MCP1. Immunology Today 11: 97-101

27. Giusti G. (1974): Adenosine deaminase. In: Bergmeyer $\mathrm{HU}$ editor. Methods of enzymatic analysis, $2^{\text {nd }}$ Ed., New York: Academic press inc., 2:1092-1099

28. Myvang G., Godal T., and Ridley D.S. (1973): Immune responsiveness to $\mathrm{M}$. leprae and other mycobacterial antigens throughout the clinical and histopathological spectrum of leprosy. Clin. Exp. Immunol., 14: 541-544

29. Britton W.J. and Lockwood D.N. (2004): Leprosy. Lancet 363:1209-1219.

30. Lockwood D.N.J., Vinayakmar S., Stanley J.N.A., McAdam K.P. and Colston M.J. (1993): Clinical features and outcome of reversal (Type 1) reactions in Hyderabad, India. Int. J. Lepr., 60:8-15.

31. Naafs B. (2000): Current views on reactions in leprosy. Indian Journal of Leprosy 72: 97-122.

32. Artieda M., Cenarro A., Gañán A., Jericó I., Gonzalvo C., Casado J.M., Vitoria I., Puzo J., Pocoví M. and Civeira F. (2003): Serum chitotriosidase activity is increased in subjects with atherosclerosis disease. Arterioscler. Thromb. Vasc. Biol., 23:1645-1652.

33. Grosso S., Margollicci M.A., Bargagli E., Buccoliero Q.R., Perrone A., Galimberti D., Morgese G., Balestri P. and Rottoli P. (2004): Serum levels of chitotriosidase as a marker of disease activity and clinical stage in sarcoidosis, Scand. J. Clin. Lab. Invest., 64:57-62.

34. Bouzas L., San Jose E. and Tutor J.C.(2007): Chitotriosidase activity in pleural effusions. Clin. Lab., 53:449452.

35. Iyer A., van Eijk M., Silva E., Hatta M., Faber W., Aerts J.M.F.G. and Das P.K. (2009): Increased chitotriosidase activity in serum of leprosy patients: Association with bacillary 
leprosy. Clinical Immunology 131: 501-509.

36. Iyer A., Hatta M., Usman R., Luiten S., Oskam L., Faber W., Geluk A. and Das P.K.(2007): Serum levels of interferongamma, tumor necrosis factoralpha, soluble interleukin-6R and soluble cell activation markers for monitoring response to treatment of leprosy reactions. Clin. Exp. Immunol., 150 210-216.

37. Immanuel C., Swamy R., Kannapiran M., Vijayalakshmi S., Sundaram V., Jagannath K. and Paramasivan C.N. (1997): Neopterin as a marker for cellmediated immunity in patients with pulmonary tuberculosis. Int. J. Tuberc. Lung Dis., 1: 175-180.

38. Silva E. A., Iyer A., Ura S., Lauris J. R., Naafs B., Das P. K. and Vilani-Moreno F. (2007): Utility of measuring serum levels of anti-PGL-I antibody, neopterin and C-reactive protein in monitoring leprosy patients during multi-drug treatment and reactions. Tropical Medicine and International Health 12(12): 1450-1458.

39. Hamerlinck, F., Faber, W.R., Klatser, P.R. and Bos, J.D. (1992): Neopterin as a marker for reactional leprosy. Exp. Dermatol., 1: 101.

40. Naafs B. (1996): Treatment of reactions and nerve damage. Int. J. Lepr. other Mycobact. Dis., 64 (Suppl.):S21-28.

41. Manandhar R., Shrestha N., Butlin C.R. and Roche P.W. (2002): High levels of inflammatory cytokines are associated with poor clinical response to steroid treatment and recurrent episodes of type 1 reactions in leprosy. Clin. Exp. Immunol., 128:333-338.

42. Raj B., Chopra R.K., Lal H., Saini A.S., Singh V. and Kumar P. (1985): Adenosine deaminase activity in pleural fluids: A diagnostic aid in tuberculous pleural effusion. Indian J. Chest Dis. Allied Sci., 27:76-80.

43. 43-Roche P.W., Britton W.J., Failbus S.S., Neupane K.D., Cho S.N. and Theuvenet W.J. (1993): Serological monitoring of the response to chemotherapy in leprosy patient. Int. J. Lepr., 61: 35-43.

44. Dayal S., Nagpal R.K., Jain V.K. and Chaudhary S.D. (1996): Adenosine deaminase activity in serum and lymphocytes of multibacillary leprosy patients. Indian J. Dermatol. Venereol. Leprol., 62:341-344.

45. Nigam $P$. K., Srivastava $P$. and Patra P. K. (2005): Serum adenosine deaminase levels in reactional and non-reactional Leprosy. Indian J. Dermatol. Venereol. Leprol., 71( 1): 20-22.

46. Chaudhary S.D., Gupta V., Saini A.S., Singh V. and Lal H. (1988): Adenosine deaminase activity in leprosy. Indian J. Lepr., 60:17-20.

47. 47-Bonecchi R., Bianchi G. and Bordignon P.P. (1998): Differential expression of chemokine receptors and chemotactic responsiveness of type $1 \mathrm{~T}$ helper cells (Th1s) and Th2s. J. Exp. Med., 187:129-134.

48. Mendonça V.A., Malaquias L.C., Brito-Melo G.E., CasteloBranco A., Antunes C.M., Ribeiro A.L., Teixeira M.M. and Teixeira A.L. (2007): 
Differentiation of Patients with Leprosy from Non-Infected Individuals by the Chemokine Eotaxin/CCL11. Am. J. Trop. Med. Hyg., 77(3):547-550.

49. Kirkaldy A.A., Musonda A.C., Khanolkhar-Young S., Suneetha S. and Lockwood D. N. J. (2003): Expression of CC and CXC chemokines and chemokine receptors in human leprosy skin lesions. Clin. Exp. Immunol., 134:447-453.

50. Stefani M.M., Guerra J.G., Sousa A.L.M., Costa M.B., Oliveira M.L.W., Martelli C.T. and Scollard D.M. (1998): Potential plasma markers of type 1 and type 2 leprosy reactions: a preliminary report. Sarcoidosis Vasc. Diffuse Lung Dis., 15(2):131-133.

51. Dhople A.M., Howell P.C., Williams S.L., Zeigler J.A. and Storrs E.E. (1985): Serum angiotensin-converting enzyme in leprosy. Indian J. Lepr., 57:282287.

52. Ramadan W.M., Hassan A.M. and El-Tatawy R.A. (2007): Study of 622 New Leprosy Patients Detected Over a Period of Twelve Years (1994-2005) in Tanta University Hospital, Gharbia, Egypt. Journal of PanArab League of Dermatologists 18(2):65-72.

\section{بعض الالالات الكيميائية الحيوية الممكنة في مرض الجذام

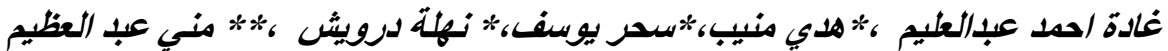

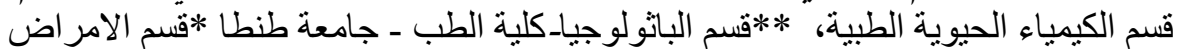

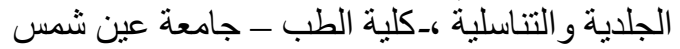

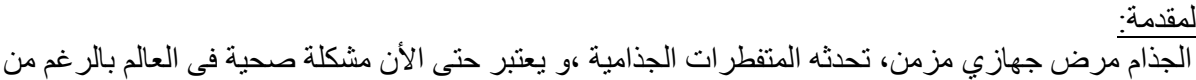

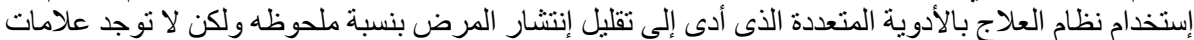

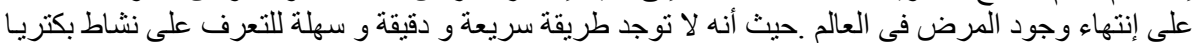

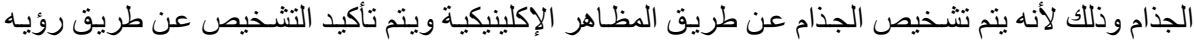

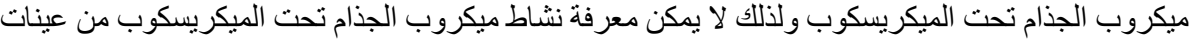

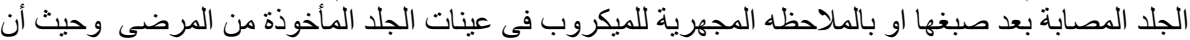

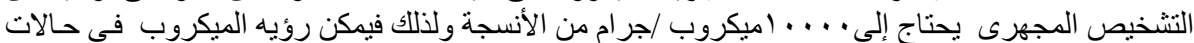

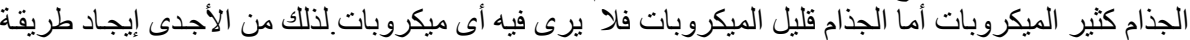

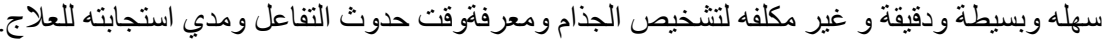

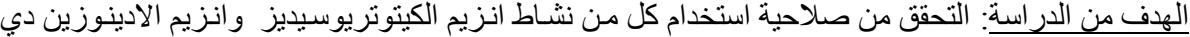

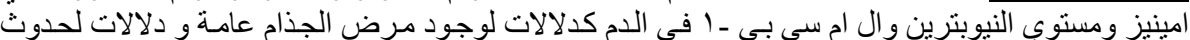

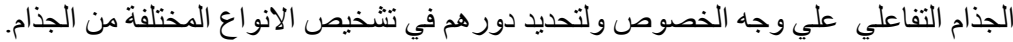

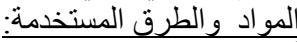

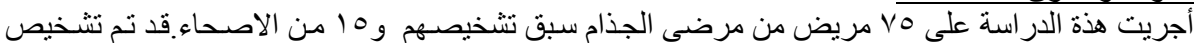

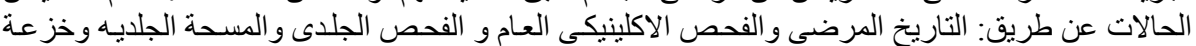

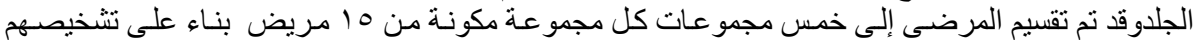

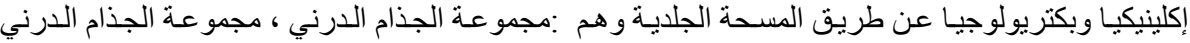




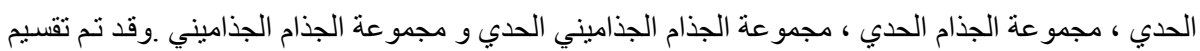

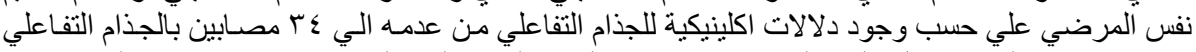

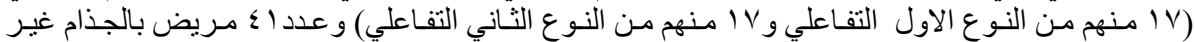

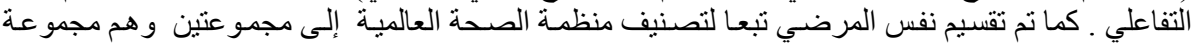

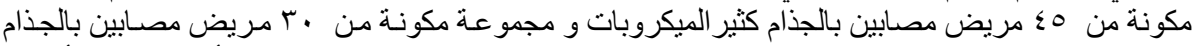

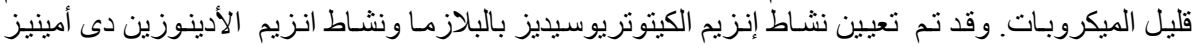

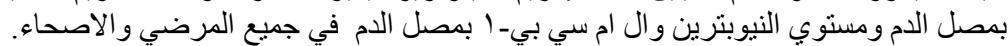

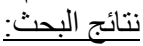

ـ اثنارت الدر استة إلى إرتفاع جميع الدالاتلات المقاسة بالدم بشكل إحصائى ملحوظ فى كل المرضى المصـابين بالجذام عن الأصحاء.

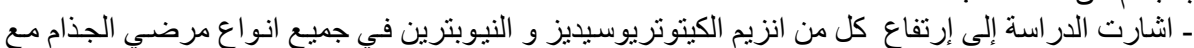

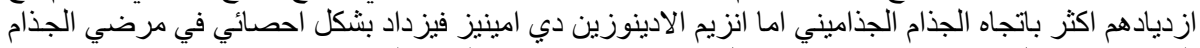

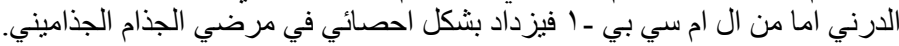

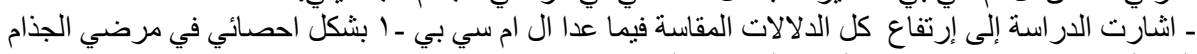

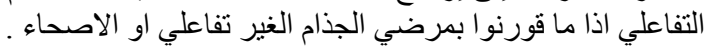

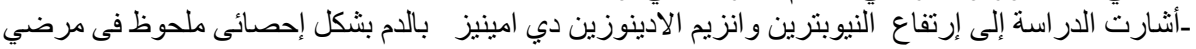

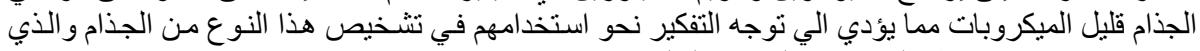

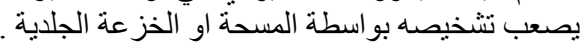

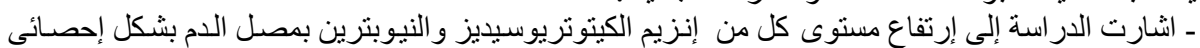

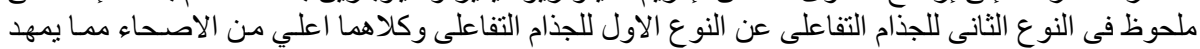

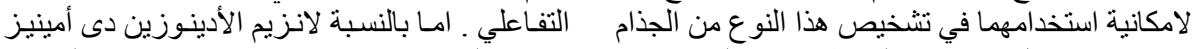

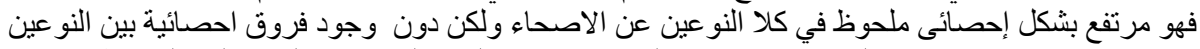

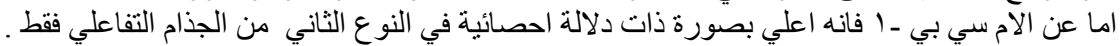

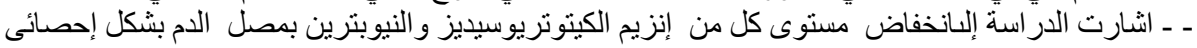

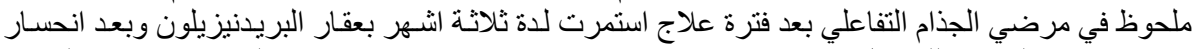

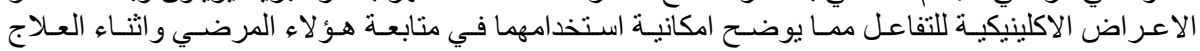

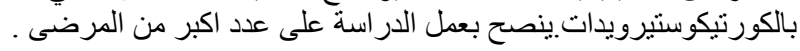

